\title{
MicroRNA-499 gene expression in Egyptian type 2 diabetes mellitus patients with and without coronary heart disease
}

\author{
Heba E. Oraby ${ }^{1 *}$, Shereen S. Elshaer ${ }^{1,2}$, Laila A. Rashed ${ }^{3}$, Noha A.Eldesoky ${ }^{1}$
}

${ }^{1}$ Department of Biochemistry and Molecular Biology, Faculty of Pharmacy (Girls), Al-Azhar University, Nasr City, Cairo, Egypt.

${ }^{2}$ Department of Biochemistry, Faculty of Pharmacy, Heliopolis University, Cairo, Egypt.

${ }^{3}$ Department of Biochemistry, Faculty of Medicine, Cairo University, Cairo, Egypt.

*Correspondence: HebaOrabi58@ hotmail.com

\section{Article history: Received 2021-06-09 Revised 2021-07-05}

Accepted 2021-07-15

\begin{abstract}
Type 2 diabetes mellitus (T2DM) is a cumulative lifelong disease with long term dangerous cardiovascular complications. MicroRNA-499 (miRNA-499) is a muscle-specific miRNA highly expressed in normal heart. This case control study was designed to assess serum levels of miRNA-499 gene expression in Egyptian T2DM patients in comparison with normal healthy volunteers and to explore its relationship with its coronary heart disease (CHD) complication. This study was performed on 180 individuals enrolled from Kasr Al-Ainy Hospital. They were divided into three groups; 60 T2DM patients with CHD, 60 T2DM patients without any complication and 60 healthy volunteers. Fasting blood glucose, HbA1c and lipid profile were assessed. Quantitative Real Time PCR was used for evaluation of miRNA-499 gene expression. Receiver Operating Characteristics (ROC) curve of miRNA-499 serum gene expression was performed to study the ability of miRNA-499 gene expression to discriminate between the studied groups. MiRNA-499 gene expression was downregulated in both diabetic groups $\left(p<0.001^{* *}\right)$ than the control group and in diabetic group with CHD complication than diabetic group without complications $\left(p<0.05^{* *}\right)$. ROC curve revealed that miRNA-499 gene expression discriminated between diabetic patients and controls with sensitivity $90 \%$ and specificity 96.6\%. MiRNA-499 gene expression discriminated also between diabetic patients with and without CHD complication with sensitivity $73 \%$ and specificity $70 \%$. MiRNA-499 downregulation was related to T2DM and its CHD complication risks. Collectively, miRNA-499 could be a beneficial biomarker for T2DM and its CHD complication and could discriminate between diabetic patients with and without CHD complication and normal individuals.
\end{abstract}

Keywords: Type 2 diabetes mellitus; Coronary heart disease; MiRNA-499; MiRNA-499 gene expression. This is an open access article distributed under the CC BY-NC-ND license https://creativecommons.org/licenses/by/4.0/

\section{INTRODUCTION}

Type 2 diabetes mellitus is a metabolic disturbance identified by hyperglycemia due to insulin resistance particularly in liver, skeletal muscle, and adipose tissue that represent a great bluster to worldwide health of individuals because of its strong connection to atherosclerotic vascular disease with significant long-term morbidity and mortality ${ }^{1,2}$. Oxidative stress is a key component in the development and progression of T2DM and its vascular complications such as $\mathrm{CHD}^{3,4}$. The plaque formation in T2DM patients causes narrowing of the coronary arteries and hence heart attacks ${ }^{5}$.

Despite significant advancements in prehospital emergency treatment and in-hospital reperfusion therapy over the past two decades, CHD is the main single reason of death globally. More than $70 \%$ of deaths in diabetics are due to heart disease or stroke ${ }^{6}$. A large ratio of this burden is found in low and middle income countries. This accounts for nearly 7 million deaths annually and is a huge global economic burden ${ }^{7}$.

Hence, it is of great importance to search for reliable and novel molecular biomarkers that are capable of predicting the onset and the progress of T2DM and could even be targeted for treatment. MicroRNAs are fundamental for gene expression regulation in several critical cellular processes such as cellular proliferation, cell cycle and apoptosis ${ }^{8}$. In tumorgenesis and their aberrations microRNAs were also found to have significant roles in cancer genesis and progression. Therefore, they are good candidates for many diseases diagnosis and therapy ${ }^{8-10}$. MicroRNAs regulate gene expression through

Cite this article: Oraby, H., Elshaer, S., Rashed, L., Eldesoky, N. (2022). MicroRNA-499 Gene Expression in Egyptian Type 2 Diabetes Mellitus Patients with and without Coronary Heart Disease.. Azhar International Journal of Pharmaceutical and Medical Sciences, 2(1),73 -81. doi: 10.21608/aijpms.2021.210569 
cleavage or inhibition of translation of target mRNAs during or after transcription ${ }^{11}$.

This work is a part of a study done on Egyptian patients suffering from type 2 diabetes mellitus with and without CHD to investigate miRNA-499 gene expression level in these groups compared to normal healthy volunteers and also to study the association of miRNA-499 rs3746444 A>G genotype variants with type 2 diabetes mellitus and its coronary heart disease complication.

The present manuscript focuses on the first part of the study which is the relation of miRNA-499 gene expression level with the studied groups, we assumed that miRNA-499 might have a role in the pathogenesis of CHD on top of T2DM as it is encoded by the myosin heavy chain 7B (MYH7B) gene located in the heart ${ }^{12,13}$. Moreover, miRNA-499 expression level in normal heart is high while in different heart diseases was found to be downregulated ${ }^{14}$.

\section{METHODS}

\subsection{Study population}

This study is a case control study that was performed on one hundred and eighty individuals. One hundred and twenty T2DM patients were recruited from the outpatient clinic of Kasr Al Ainy Hospital. Patients were diagnosed clinically then categorized into two groups; sixty T2DM patients without any complication and sixty T2DM patients with CHD. Diabetes mellitus was defined as a fasting blood glucose $(\mathrm{FBG}) \geq 126 \mathrm{mg} / \mathrm{dl}(7.0 \mathrm{mmol} / \mathrm{L})$ or HbAlc $\geq 6.5 \%(48 \mathrm{mmol} / \mathrm{mol})^{15}$. Sixty healthy volunteers (sex and age matched with the patients' groups) were enrolled as a control group. A written approval was taken from all participants. The study was approved by the ethics committee of the Faculty of Pharmacy (Girls), Al-Azhar University (REC no. 254). Patients suffering from type 1 diabetes mellitus, any type of cancer, liver and kidney diseases, any metabolic disorders that may affect the studied biochemical parameters or any other diabetic complications than CHD were excluded.

\subsection{Samples collection}

Ten $\mathrm{ml}$ of blood were withdrawn from every participant under complete aseptic conditions after an overnight fasting (12 hours) and divided into three portions: Two $\mathrm{ml}$ were collected in fluoride coated tube for determination of fasting blood glucose (FBG), Three ml were collected in EDTA tube and mixed gently for glycated hemoglobin assay (HbA1c) on fresh whole blood and three ml were left at room temperature to clot, centrifuged for 15 minutes at $3000 \mathrm{rpm}$ then serum was detached, divided into aliquots and kept at $-80^{\circ} \mathrm{c}$ until assessment of the lipid profile, liver and kidney function tests, and miRNA-499 gene expression.

2.3. Quantitative real-time polymerase chain reaction for serum gene expression of miRNA-499

MicroRNA was extracted from serum samples using mirvana kit USA (catalog no. AM1560). The isolated miRNA was reverse transcribed into cDNA using specific miRNA primers for miRNA assay and reagents (TaqMan® MicroRNA Reverse Transcription Kit (catalog no. 4366596). Each $15 \mu \mathrm{L}$ RT reaction consisted of $7 \mu \mathrm{L}$ master mix, $3 \mu \mathrm{L}$ primer and $5 \mu \mathrm{L}$ RNA sample with performing the following thermal condition; the temperature was held at $16^{\circ} \mathrm{C}$ for 30 minutes, then at $42^{\circ} \mathrm{C}$ for 30 minutes and finally at $85{ }^{\circ} \mathrm{C}$ for 5 minutes. Amplification of cDNA was carried out on step-one real- time PCR system by AmpliTaq Gold DNA polymerase (catalog no. N8080240).

Analysis of data was done by relative quantification using $2^{-\Delta \Delta c t}$ method. In this method, data was offered as the fold change in microRNA expression normalized to an endogenous control and relative to the healthy groups.

$\Delta \mathrm{CT}=\mathrm{CT}$ (miRNA-499) - CT (endogenous control) $\Delta \Delta \mathrm{CT}=\Delta \mathrm{CT}$ (patient) $-\Delta \mathrm{CT}$ (healthy groups)

Fold Change or $(\mathrm{Rq})=2-\Delta \Delta \mathrm{CT}$

Table 1. Sequences of the primers used for real time PCR:

\begin{tabular}{lll}
\multicolumn{1}{c}{ Genes } & \multicolumn{1}{c}{ Primers Sequence } & $\begin{array}{c}\text { Gene bank accession } \\
\text { number }\end{array}$ \\
\hline MiRNA-499 & Forward primer: 5'-CAA AGT CTT CAC TTC CCT GCC A-3' & NR_039912.1 \\
& Reverse primer: 5'-GAT GTT TAA CTC CTC TCC ACG TGA TC-3' & \\
\hline Housekeeping & "Forward primer: 5-GGAACGATACAGAGAAGATTAGC-3" & XR_005231505.1 \\
miRNA; RU6 & "Reverse primer: 5-TGGAACGCTTCACGAATTTGCG-3" & \\
\hline
\end{tabular}

\subsection{Statistical Analysis}

Statistical Package for Social Science (SPSS) version 26 was used for data entry and statistical analysis. Qualitative data were represented by frequencies and percentages while quantitative data were represented by mean, median and standard deviation (SD) to measure central tendency and dispersion of quantitative data. Chi square $\left(\mathrm{X}^{2}\right)$ test was used for the comparison between qualitative data, Odds ratio (OR) with $95 \%$ confidence intervals were calculated. Independent t-test was used for the comparison between two quantitative data and ANOVA for the comparison between more than two quantitative data. Ranked spearman correlation was 
used to assess the association between serum expression levels of miRNA-499 and some risk factors. Level of significance was taken at $p$-value $<0.05$. The Receiver Operating Characteristics (ROC) curve was constructed using MedCalc version 14 to obtain the most sensitive and specific cutoff values that could discriminate between groups, area under the curve (AUC) have been also calculated.

\section{RESULTS}

3.1. Baseline characteristics of the study population

All the studied individuals were matched in the baseline characters (age, sex and BMI). There was a highly significant increase in FBG level of both diabetic groups when compared to the control group $(P<0.001)$. Also, upon comparing the HbA1c\% of both diabetic groups with controls, there was a highly significant increase in the former groups $(P<0.001)$ (figures 1,2). Consistently, there was an extremely significant increase in triglycerides, total cholesterol and LDL-C on comparing both diabetic groups with the control group $(P<0.001)$ but, there was a highly significant decrease in HDL-C on comparing both diabetic groups with the control group $(P<0.001)$ (figure 3).

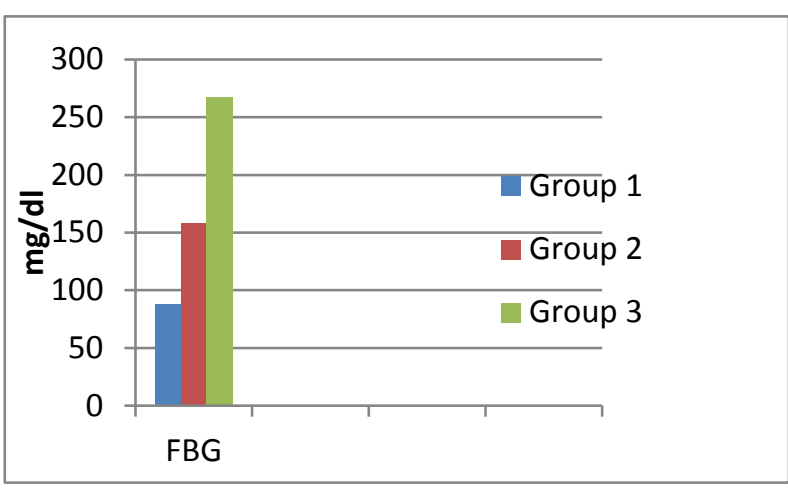

Figure 1: Fasting blood glucose of the studied groups.

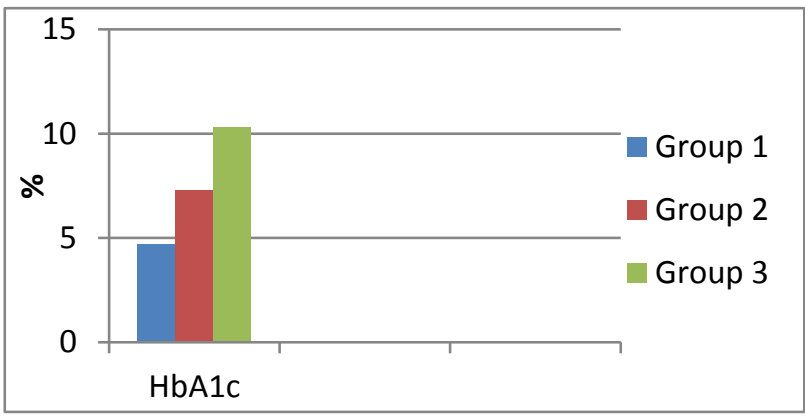

Figure 2: HbA1c of the studied groups.

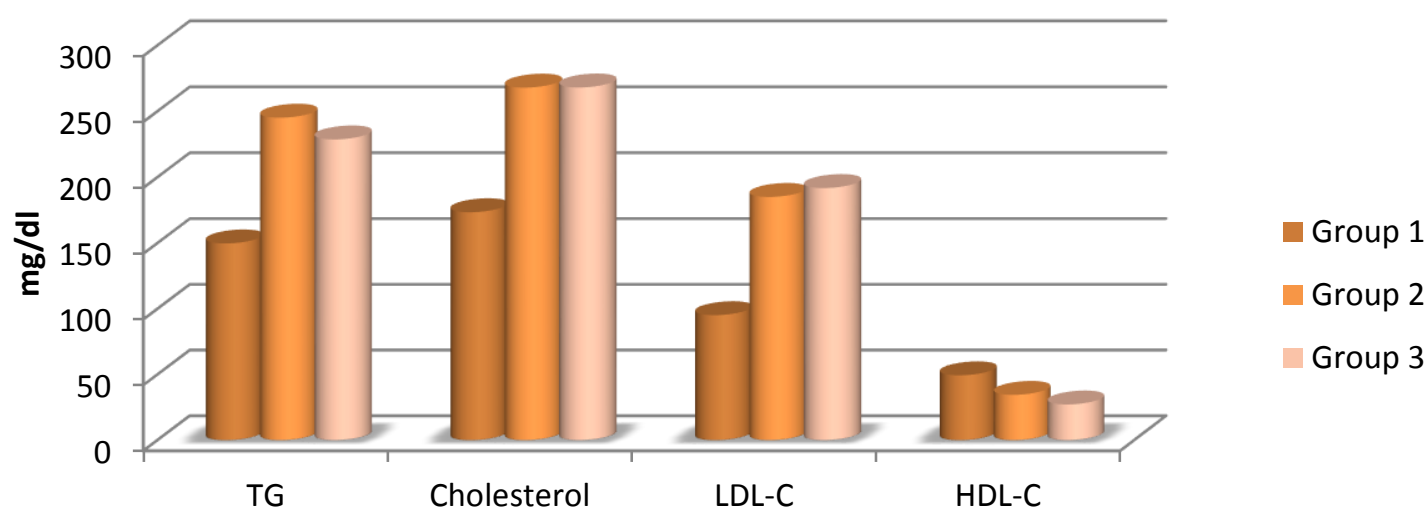

Figure 3: Lipid profile of the studied groups.

\section{2. miRNA-499 gene expression level of the} study population

Regarding miRNA-499 gene expression, there was a highly significant reduction in its serum gene expression level in both diabetic groups compared to the control group $(P<0.001)$ and a significant lowered gene expression level in type 2 diabetic patients with CHD than type 2 diabetic patients without complications $(P<0.05)$ (Table 2$)$.
3.3. Receiver Operating Characteristics (ROC) curve of miRNA-499

Receiver Operating Characteristics (ROC) curve of serum gene expression level of miRNA499 for discrimination between diabetic patients and controls revealed an AUC of 0.97 with sensitivity $90 \%$ and specificity $96.6 \%(P<0.0001)$. ROC curve of serum gene expression level of miRNA-499 for discrimination between diabetic patients with and without CHD complication revealed an AUC of 0.72 with sensitivity $73 \%$ and specificity $70 \%$ $(P<0.0001)$ (Tables 3, 4) (figures 4, 5). 
Table 2: Median of serum miRNA-499 gene expression level of the studied groups.

\begin{tabular}{|c|c|c|c|c|}
\hline \multirow{2}{*}{ Parameters } & \multirow{2}{*}{$\begin{array}{l}\text { Controls } \\
\text { Group } 1 \\
\mathrm{~N}=60\end{array}$} & \multicolumn{2}{|c|}{ Diabetic Patients } & \multirow[b]{2}{*}{$p$-value } \\
\hline & & $\begin{array}{l}\text { Group } 2 \\
\mathrm{~N}=60\end{array}$ & $\begin{array}{l}\text { Group } 3 \\
\mathrm{~N}=60\end{array}$ & \\
\hline \multicolumn{5}{|l|}{ RQ miRNA-499 } \\
\hline $\begin{array}{l}\text { Median } \\
\left(1^{\text {st }} \text { quartile- } 3^{\text {rd }} \text { quartile }\right)\end{array}$ & $\begin{array}{l}1.18 \\
(0.96-1.5)\end{array}$ & $\begin{array}{l}0.479^{\mathrm{a}} \\
(0.34-0.69)\end{array}$ & $\begin{array}{l}0.327^{\mathrm{a}, \mathrm{b}} \\
(0.2-0.46)\end{array}$ & $p<0.001^{* *}$ \\
\hline
\end{tabular}

Group 1: Control group; Group 2: T2DM patients without complications; Group 3: T2DM patients with CHD.

a: significance from group 1

b: significance from group 2

* Significant at $p \leq 0.05, * *$ highly significant at $p \leq 0.001$.

Table 3: ROC curve of serum miRNA-499 gene expression for discrimination between diabetic patients and controls.

\begin{tabular}{ccccc}
\hline AUC & Cutoff point & \%Sensitivity & \%Specificity & $\boldsymbol{p}$-value \\
\hline $\mathbf{0 . 9 7}$ & 0.70 & 90 & 96.6 & $p<0.0001$ \\
\hline
\end{tabular}

Table (4): ROC curve of serum miRNA-499 gene expression for prediction of CHD complication in diabetic patients.

\begin{tabular}{ccccc}
\hline AUC & Cutoff point & \%Sensitivity & \%Specificity & $\boldsymbol{p}$-value \\
\hline $\mathbf{0 . 7 2}$ & 0.40 & 73 & 70 & $p<0.0001$ \\
\hline
\end{tabular}

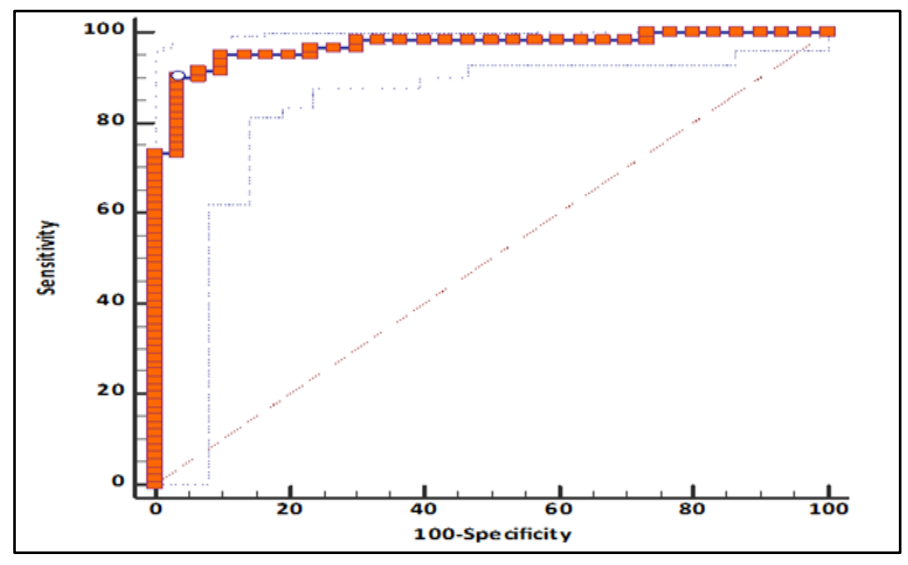

Figure 4. ROC curve of serum miRNA-499 gene expression for discrimination between diabetic patients and controls.

3.4. Correlation of miRNA-499 gene expression with the studied parameters among all the studied diabetic patients:

A significant negative correlation was obtained between miRNA-499 gene expression and each of FBG $(\mathrm{mg} / \mathrm{dl})$ and $\mathrm{HbAlc}(\%)$ among the studied diabetic patients $(p<0.001)$ (table 5).

\section{DISCUSSION}

Type 2 diabetes mellitus is among the most rapidly growing global health emergencies ${ }^{16}$. It has been the main cause of death in the developed world for many years ${ }^{17}$.

Hyperglycemia, insulin resistance and hyperinsulinemia in T2DM accelerate atherosclerosis as they are associated with more atherogenic dyslipidemia which stimulates leukocyte and platelet sticking together, clotting, inflammation and coronary plaque ulceration ${ }^{18}$.

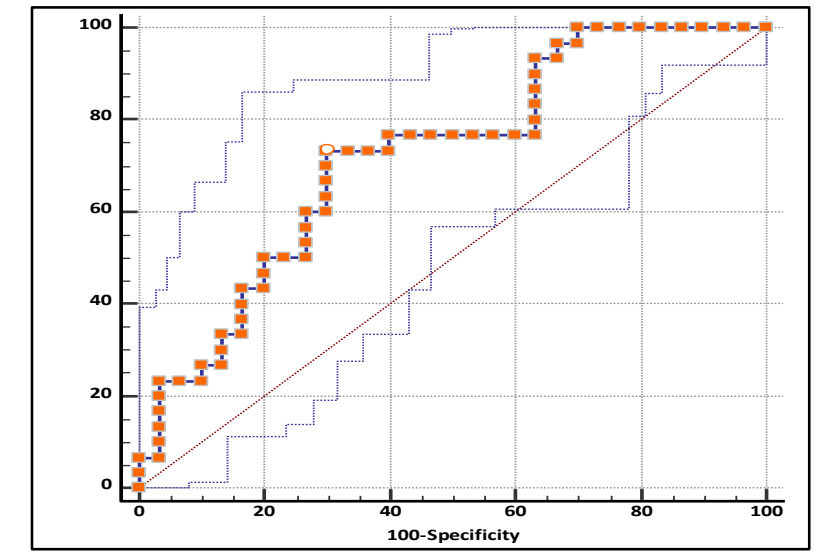

Figure 5. ROC curve of serum miRNA-499 gene expression for prediction of CHD complication in diabetic patients.

MicroRNAs play vital roles in various biological processes under physiological conditions or pathological disorders as they are involved in metabolism, development, immune response, tumorigenesis, metastasis, diabetes mellitus, cardiovascular diseases, apoptosis and autophagy ${ }^{19,20}$. Recently, miRNAs were proven to be promising candidate biomarkers in cardiovascular diseases as they are noninvasive parameters that can be easily detected in body fluids (blood, urine, etc.) due to their remarkable stability and presence in apoptotic bodies and exosomes ${ }^{21}$.

In the current study, all groups were matched in the baseline characters avoiding selection bias. Fasting blood glucose and glycated hemoglobin were significantly highly increased in diabetic patients' groups in comparison with the control group and significantly highly increased in the diabetic group with CHD complication than without complications $(p<0.001)$ (figures 1,2$)$. These results were in 
harmony with the criteria reported by the American Diabetes Association for the diagnosis of DM which states that a diabetic patient has either FBG $<126$ $\mathrm{mg} / \mathrm{dl}$, or $\mathrm{HbA} 1 \mathrm{c}<6.5 \%{ }^{22}$. Besides, glycated hemoglobin test is the most common diagnostic and screening tool used for T2DM monitoring and research and is considered the gold standard of diabetic care in contemporary clinical practice ${ }^{23}$. In the present study, both diabetic groups showed significantly higher TG, Cholesterol and LDL-C levels and significantly lowered HDL-C level as compared to the control group (figure 3). However, no significant differences were obtained between both diabetic groups regarding lipid profile; this could be explained by the hypo-cholesterolemic drugs taken by diabetic patients with CHD.

Table 5: Correlation of miRNA-499 gene expression with the studied parameters among all studied diabetic patients.

\begin{tabular}{|c|c|c|}
\hline \multirow[t]{2}{*}{ Parameters } & \multicolumn{2}{|c|}{$\begin{array}{l}\text { MiRNA-499 gene expression level in the studied diabetic patients } \\
\qquad n=120\end{array}$} \\
\hline & r-value & $p$-value \\
\hline Age (years) & -0.181 & $0.048^{*}$ \\
\hline Weight (kg) & -0.029 & 0.756 \\
\hline Height (m) & -0.141 & 0.124 \\
\hline BMI $\left(\mathrm{Kg} / \mathrm{m}^{2}\right)$ & 0.083 & 0.368 \\
\hline ALT (U/L) & 0.101 & 0.271 \\
\hline AST (U/L) & 0.193 & 0.305 \\
\hline Urea (mmol/L) & -0.003 & 0.972 \\
\hline Creatinine (mg/dl) & 0.11 & 0.23 \\
\hline FBG (mg/dl) & -0.346 & $<0.001^{* *}$ \\
\hline HbA1c (\%) & -0.404 & $<0.001^{* *}$ \\
\hline TG (mg/dl) & 0.113 & 0.219 \\
\hline $\begin{array}{l}\text { Total Cholesterol } \\
\text { (mg/dl) }\end{array}$ & 0.009 & 0.921 \\
\hline HDL-C (mg/dl) & 0.066 & 0.476 \\
\hline LDL- C (mg/dl) & -0.014 & 0.876 \\
\hline
\end{tabular}

$*$ Significant at $p \leq 0.05, * *$ highly significant at $p \leq 0.001$.

These results came in accordance with Mellor et al., who defined type 2 diabetes mellitus as a condition of hyperglycemia associated with suppressed HDL cholesterol ${ }^{24}$. Also, Al Mahmeed et al., reported that hyperlipidemia was widely spread in patients with $\mathrm{CHD}^{25}$.

This case control study was designed to evaluate miRNA-499 serum gene expression levels in Egyptian T2DM patients with and without CHD compared to normal healthy volunteers.

In previous studies, miRNA-499 was found to be expressed in normal heart and circulating miRNA499 was suggested to be a sensitive biomarker for acute myocardial infarction ${ }^{13}$. It was also found to protect cardio-myocytes from $\mathrm{H}_{2} \mathrm{O}_{2}$ induced apoptosis $^{26}$.

MicroRNAs have been proved to be implicated in the regulation of the pancreatic $\beta$-cells function, insulin-signaling pathways, glucose stimulated insulin secretion, autophagy/apoptosis interplay and other biological behaviors related to glucose metabolism disorders making them ideal candidates for unearthing T2DM molecular complexities ${ }^{27,28}$. This comes in line with the present study as serum gene expression of miRNA-499 in both T2DM groups revealed significantly lowered levels than that in the control group. Moreover, its values were significantly lowered in T2DM with CHD than those without complications $(p<0.001)$ (table, 2). These results were agreed with Mohsen et al., who stated that hyperglycemia induces miRNA-499 downregulation and explained their results with increased oxidative stress. They added that miRNA-499 downregulation mediated diabetic cardiomyopathy ${ }^{29}$. Also, Chavali et al., reported down regulation of miRNA499 in diabetic hearts, suggesting miRNA-499 as a putative candidate implicated in the pathophysiology of diabetic heart disease ${ }^{30}$. Yildirim et al., reported that miRNA-499 down-regulation have mediated diabetic cardiomyopathy and suggested that hyperglycemia induced miRNA-499 down regulation $^{31}$.

Hathaway et al., found a link between extreme ROS production in STZ-induced diabetic cardiomyopathy and decreased expression of miRNA-49932. Huang et al., explained that in $\mathrm{db} / \mathrm{db}$ mice's livers, the downregulated miRNA-499-5p diminished the glycogen synthesis and insulin signaling pathways ${ }^{33}$. Moreover, Nigi et al., stated that miRNA-499-5p was decreased in pancreatic islets from insulin resistant rodent models via directing apoptosis-associated tyrosine kinase (AATK). They found miRNA-499-5p could 
compensate $\beta$-cell mass expansion. Moreover, they demonstrated that miRNA-499-5p directly targets PTEN phosphatase ${ }^{34}$.

It was simply expected that endothelial activation associated with coronary artery disease (CAD) would induce the liberation of micro particles and remnants of apoptotic cells, thereby elevating the miRNAs levels. However, Zernecke et al. explained that miRNA can reach the atherosclerotic lesion via apoptotic bodies. Therefore, they speculated that the reduction in circulating miRNAs seen in patients with CHD might be caused by the uptake of freely movable miRNAs from the circulation into the atherosclerotic lesions ${ }^{35}$.

In order to show the discriminative power of miRNA-499 between control group and diabetic groups, Receiver Operating Characteristics (ROC) curve was carried out and showed specificity $96.6 \%$ and sensitivity $90 \%$ at cut off value 0.70 and AUC 0.97. Also, ROC curve for discrimination between both diabetic patients' groups (with and without cardiac complications) showed specificity $70 \%$ and sensitivity $73 \%$ at cut off value 0.40 with AUC 0.72 , tables $(3,4)$, figures $(4,5)$. Hence, miRNA-499 could be considered as a beneficial diagnostic biomarker for discrimination between diabetic patients and normal individuals and also between diabetic patients with and without CHD complication.

These results were agreed with previous researches that studied the relation of miRNA-499 with cardiac diseases, such as a study on Egyptian population by Fawzy et al., who reported that circulating miRNA-499a could function as a useful biomarker in discriminating acute MI from healthy volunteers within 12 hours $^{36}$ and another two studies by Mayr et al., and Zhao et al., who reported that miRNA-499 was a worthy diagnostic and/or prognostic marker across different cardiovascular disease progression stages ${ }^{37,13}$. Also, Wang et al., reported that miRNA-499 had a high diagnostic efficiency for prediction of acute coronary syndrome $(\mathrm{ACS})^{38}$.

In the current study, the correlation between miRNA-499 gene expression, and clinical data among the studied DM patients (with and without CHD) revealed a negative significant correlation between miRNA-499 gene expression and each of age, FBG and HbAlc (table 5). The decline in the levels of miRNA-499 with age was expected as proceeding in age is well known to be accompanied with an increase in the incidence and prevalence of diabetes mellitus and its CHD complication. ${ }^{39,} 40$ Furthermore, in agreement with our results, Fluitt et al., found a negative significant correlation between miRNA-499 gene expression and HbA1c in African American pre-diabetic adults. They considered miRNA-499 a hopeful biomarker for early DM diagnosis, and added that miRNA-499 targeted
PTEN and was involved in both insulin and glucose tolerance ${ }^{41}$.

\section{CONCLUSIONS}

According to the studied Egyptian population, miRNA-499 seemed to exert a protective activity against T2DM and its CHD complication. Its downregulation could play a role in the pathogenesis of both. Also, miRNA-499 could be a beneficial biomarker for discrimination between diabetic patients with and without CHD complication and normal individuals.

Funding: This research did not receive any specific grant from funding agencies in the public, commercial, or not-for-profit sectors.

Acknowledgment: The authors would like to express their gratitude to PCR lab technicians, Faculty of Medicine, Cairo University for their great help during the practical part of the study.

Conflicts of Interest: The authors report no conflict of interest.

Ethical Statement: The present work was approved by the Research Ethical Committee of the Faculty of Pharmacy (Girls), Al-Azhar University, Cairo, Egypt (REC number: 254).

Author Contribution: This work was carried out in collaboration between all authors. HEO: methodology, formal analysis and writing the manuscript. NAE: data analysis, visualization, validation, editing manuscript, and gaining ethical approval. SSE: supervision, data analysis and editing the manuscript. LAR: the practical part and data curation. All authors have read and approved the final manuscript.

List of Abbreviations: T2DM: Type 2 diabetes mellitus, miRNA-499: microRNA-499, CHD: Coronary heart disease, ROC: Receiver operating characteristics, FBG: Fasting blood glucose, HbA1c: Glycated hemoglobin, MYH7B: Myosin heavy chain 7B, AUC: Area under the curve, SPSS: Statistical package for social science, SD: Standard deviation, CAD: Coronary Artery Disease, AATK: Apoptosis-associated tyrosine kinase, ACS: Acute coronary syndrome, mRNA: Messenger RNA.

\section{REFERENCES}

1. Ferrannini G, Norhammar A, Gyberg V, Mellbin L, Rydén L. Is Coronary Artery Disease Inevitable in Type 2 Diabetes? From a Glucocentric to a Holistic View on Patient Management.ADA . 2020; 43(9): 2001-2009.https://doi.org/10.2337/dci200002 
2. Albosta $\mathbf{M}$, Bakke $\mathbf{J}$. Intermittent fasting: is there a role in the treatment of diabetes? A review of the literature and guide for primary care physicians. Clinical diabetes and endocrinology. 2021; 7(1): 1-12.

3. Oguntibeju OO. Type 2 diabetes mellitus, oxidative stress and inflammation: examining the links. International journal of physiology. Pathophysiology and pharmacology. 2019; 11(3): 45.

4. Yaribeygi H, Sathyapalan T, Atkin SL and Sahebkar A. Molecular Mechanisms Linking Oxidative Stress and Diabetes Mellitus. Oxidative Medicine and Cellular Longevity; 2020: 8609213. https://doi.org/10.1155/2020/8609213.

5. Gong R, Chen M, Zhang C, Chen $\mathrm{M}$ and Li H. A comparison of gene expression profiles in patients with coronary artery disease, type 2 diabetes, and their coexisting conditions. Diagnostic pathology. 2017; 12(1): 44.

6. Aronson D and Edelman ER. Coronary artery disease and diabetes mellitus. Cardiology clinics.2014; 32(3): 439455.https://doi.org/10.1016/j.ccl.2014.04.0 01

7. Ralapanawa U, Sivakanesan R. Epidemiology and the Magnitude of Coronary Artery Disease and Acute Coronary Syndrome: A Narrative Review. Journal of Epidemiology and Global Health.2021.

DOI: https://doi.org/10.2991/jegh.k.201217.001.

8. Pan CY, Lin WC. miR-TV: an interactive microRNA Target Viewer for microRNA and target gene expression interrogation for human cancer studies. Database. 2020; 148.

https://doi.org/10.1093/database/baz148.

9. Suwanwongse K, Shabarek N. miRNA125b Downregulation: A Review of the Novel Paradigm of Psoriasis Epigenetic Regulation. Cureus. 2020; 12(1): e6798. doi: 10.7759/cureus.6798.

10. Crouser ED, Julian MW, Bicer S, Ghai V, Kim TK, Maier LA, et al. Circulating exosomal microRNA expression patterns distinguish cardiac sarcoidosis from myocardial ischemia. Plos one.2021; 16(1): e0246083.

https://doi.org/10.1371/journal.pone.02460 83

11. Krishnatreya DB, Agarwala N, Gill SS, Bandyopadhyay T. Understanding the role of miRNAs for improvement of tea quality and stress tolerance. Journal of Biotechnology. 2021; 328: 34-46. https://doi.org/10.1016/j.jbiotec.2020.12.0 19

12. Peter AK, Rossi AC, Buvoli M, Ozeroff CD, Crocini C, Perry AR, et al. Expression of Normally Repressed Myosin Heavy Chain 7b in the Mammalian Heart Induces Dilated Cardiomyopathy. JAHA.2019; 8(15): e013318. https://doi.org/10.1161/JAHA.119.

13. Zhao J, Yu H, Yan P, Zhou X, Wang Y, Yao Y. Circulating MicroRNA-499 as a diagnostic biomarker for acute myocardial infarction: a meta-analysis. Disease markers.2019; 6121696:10. https://doi.org/10.1155/2019/6121696.

14. Chistiakov DA, Orekhov AN, Bobryshev YV. Cardiac-specific miRNA in cardiogenesis, heart function, and cardiac pathology (with focus on myocardial infarction). Journal of molecular and cellular cardiology.2016; 94: 107-121. https://doi.org/10.1016/j.yjmcc.2016.03.01 5.

15. American Diabetes Association. 6. Glycemic targets: standards of medical care in diabetes-2018. Diabetes care. 2018; 41(1): S55-S64. https://doi.org/10.2337/dc18-S006.

16. Yu M, Zhan $\mathrm{X}$, Yang $\mathrm{Z}$, Huang $\mathrm{Y}$. Measuring the global, regional, and national burden of type 2 diabetes and the attributable risk factors in all 194 countries. Journal of Diabetes. 2021. https://doi.org/10.1111/1753-0407.13159.

17. Flor-de-Liz Pérez-Losada E, Jané-Salas MDMS, Recolons AED, Juan-José Segura-Egea JL. Correlation between periodontal disease management and metabolic control of type 2 diabetes mellitus. A systematic literature review. Medicina oral, patologia oral y cirugia bucal.2016; 21(4): e440. 
18. Dunlay SM, Givertz MM, Aguilar D, Allen LA, Chan M, Desai AS, et al. Type 2 Diabetes Mellitus and Heart Failure: A Scientific Statement from the American Heart Association and the Heart Failure Society of America: This statement does not represent an update of the 2017 ACC/AHA/HFSA heart failure guideline update. Circulation.2019; 140(7): e294e324.

https://doi.org/10.1161/CIR.000000000000 0691

19. Kim J, Yao F, Xiao Z, Sun Y and Ma L. MicroRNAs and metastasis: small RNAs play big roles. Cancer and Metastasis Reviews. 2018; 37(1): 5-15.

20. Elfaki I, Mir R, Mir MM, AbuDuhier FM, Babakr AT, Barnawi J. Potential Impact of MicroRNA Gene Polymorphisms in the Pathogenesis of Diabetes and Atherosclerotic Cardiovascular Disease. Journal of personalized medicine. 2019; 9(4):

51. https://doi.org/10.3390/jpm9040051

21. Mir R, Elfaki I, Khullar N, Waza AA, Jha C, Mir MM, et al. Role of Selected miRNAs as Diagnostic and Prognostic Biomarkers in Cardiovascular Diseases, Including Coronary Artery Disease, Myocardial Infarction and Atherosclerosis. Journal of Cardiovascular Development and Disease.2021; $\quad 8(2)$ : 22. https://doi.org/10.3390/jcdd8020022

22. American Diabetes Association. 2. Classification and Diagnosis of Diabetes: Standards of Medical Care in Diabetes2020. Diabetes Care.2020; 43(1): S14-S31. https://doi.org/10.2337/dc20-S002

23. Yonel Z, Batt J, Jane R, Cerullo E, Gray LJ, Dietrich $\mathrm{T}$, et al. The Role of the Oral Healthcare Team in Identification of Type 2 Diabetes Mellitus: A Systematic Review. Current Oral Health Reports. 2020; 7: 8797.

24. Mellor DD, Georgousopoulou EN, D'Cunha NM, Naumovski N, Chrysohoou C, Tousoulis D, et al. Association between lipids and apolipoproteins on type 2 diabetes risk; moderating effects of gender and polymorphisms; the ATTICA study. Nutrition, Metabolism and Cardiovascular Diseases.2020; $\quad 30(5): \quad$ 788-795. https://doi.org/10.1016/j.numecd.2020.01. 008

25. Al Mahmeed W, Bakir S, Beshyah SA, Morcos B, Wajih S, Horack M, et al. Prevalence of Lipid Abnormalities and Cholesterol Target Value Attainment in Patients with Stable and Acute Coronary Heart Disease in the United Arab Emirates. Heart Views: The Official Journal of the Gulf Heart Association.2019; 20(2): 3746.https://dx.doi.org/10.4103\%2FHEART VIEWS.HEARTVIEWS $32 \_18$

26. Li Y, Lu J, Bao X, Wang X, Wu J, Li X.et al. MiR-499-5p protects cardiomyocytes against ischaemic injury via anti-apoptosis by targeting PDCD4. Oncotarget.2016; 7(24): 35607-35617. doi: 10.18632/oncotarget.9597

27. Elshaer SS, Eldesoky NAR, ELdosoky MAR, Zahran FE, Eladawy EH. (2018): MiR-216a in Diabetic Nephropathy: Relation with Autophagy and Apoptosis. International Journal of Pharmaceutical Research \& Allied Sciences; 7: (1):15_24.

28. Aghaei M, Khodadadian A, Elham KN, Nazari M, Babakhanzadeh E. Major miRNA Involved in Insulin Secretion and Production in Beta-Cells. International Journal of General Medicine. 2020; 13: 8997.

https://dx.doi.org/10.2147\%2FIJGM.S249 011.

29. Mohsen IH, Zaidan HK, Nassir IM, AlSaadi AH, Al-Terehi MN, Al-Jboori MJ. Association of mir-499 gene polymorphism with some hormones in type 2 diabetes mellitus patients. Indian Journal of Public Health Research \& Development.2018; 9(11): 1921-1925.

30.Chavali V, Tyagi SC, Mishra PK. Differential Expression of Dicer, miRNAs, and Inflammatory Markers in Diabetic Ins2+/- Akita Hearts. Cell biochemistry and biophysics.2014; 68(1): 25-35.

31. Yildirim SS, Akman D, Catalucci D, Turan B. Relationship between downregulation of miRNAs and increase of oxidative stress in the development of diabetic cardiac dysfunction: junctin as a target protein of 
miR-1. Cell biochemistry and biophysics.2013; 67(3): 1397-1408.

32. Hathaway QA, Pinti MV, Durr AJ, Waris S, Shepherd DL, Hollander J M. Regulating microRNA expression: at the heart of diabetes mellitus and the mitochondrion. American Journal of Physiology-Heart and Circulatory Physiology.2018; 314(2): H293-H310.

33. Huang Y, Yan Y, Xv W, Qian G, Li C, Zou $\mathrm{H}$, et al. A new insight into the roles of MiRNAs in metabolic syndrome. BioMed research international.2018; 7372636: 15.

34. Nigi L, Grieco GE, Ventriglia G, Brusco N, Mancarella F, Formichi C, et al. MicroRNAs as regulators of insulin signaling: research updates and potential therapeutic perspectives in Type 2 diabetes. International journal of molecular sciences.2018; 19(12): 3705 .

35. Zernecke A, Bidzhekov K, Noels H, Shagdarsuren E, Gan L, Denecke B, et al. Delivery of microRNA-126 by apoptotic bodies induces CXCL12-dependent vascular protection. Sci Signal.2009; 2(100):ra81.

36. Fawzy MS, Toraih EA, Hamed EO, Hussein MH, Ismail HM. Association of MIR-499a expression and seed region variant (rs3746444) with cardiovascular disease in
Egyptian patients. Acta cardiologica.2018; 73(2), 131-140.

37. Mayr B, Niebauer J and Breitenbach-Koller H. (2019): Circulating miRNAs as predictors for morbidity and mortality in coronary artery disease. Molecular biology reports; 46: 5661-5665.

38. Wang XY, Zhang F, Zhang C, Zheng LR, Yang J. The Biomarkers for Acute Myocardial Infarction and Heart Failure. BioMed Research International.2020; 2018035.

39. Mize, B. M., Duke, B., Pangle, A. K., Wei, J. Y., \& Azhar, G. (2021). Cardiovascular Health in Individuals with Exceptional Longevity Residing in Arkansas. Gerontology and Geriatric Medicine, 7, 23337214211018933. 40. American Diabetes Association. (2021). 12. Older adults: standards of medical care in diabetes-2021. Diabetes Care, 44(Supplement 1), S168-S179.

40. Fluitt, M. B., Kumari, N., Nunlee-Bland, G., Nekhai, S., \& Gambhir, K. K. (2016). miRNA-15a, miRNA-15b, and miRNA499 are Reduced in Erythrocytes of PreDiabetic African-American Adults. Jacobs journal of diabetes and endocrinology, 2(1), 014 